Chapter 5

\title{
Bovine Papillomaviruses - Taxonomy and Genetic Features
}

\author{
Michele Lunardi, Amauri Alcindo Alfieri, \\ Rodrigo Alejandro Arellano Otonel and \\ Alice Fernandes Alfieri \\ Additional information is available at the end of the chapter \\ http://dx.doi.org/10.5772/56195
}

\section{Introduction}

Papillomaviruses (PVs) are epitheliotropic viruses that cause benign proliferative lesions in the skin (warts or papillomas) and mucous membranes (condylomas) of their natural hosts. However, certain malignant epithelial lesions have been attributed to PVs, especially in cases of cervical cancer and other human urogenital tract tumors [1].

The first DNA oncovirus recognized was also the first animal PV to be identified. Known as CRPV (cottontail rabbit papillomavirus), this virus was identified in the 1930s in warts on the skin of cottontail rabbits [2].

PVs are small, non-enveloped, icosahedral viruses that replicate in the nuclei of squamous epithelial cells. The diameter of the viral particles varies between 52 and $55 \mathrm{~nm}$ (Figure 1) $[1]$.

Currently, PVs constitute a widely diverse group of DNA viruses. PVs have been found in many mammal species, as well as in certain birds and reptiles. In addition to human beings (human papillomavirus - HPV), PVs have been identified in most domestic animals, including bovines (BPV), canines (CPVs), goats (Capra hircus papillomavirus - ChPV1), equines (Equus caballus papillomavirus EcPVs), domestic felines (Felis domesticus papillomavirus - FdPV), sheep (Ovis aries papillomavirus - OaPV), and swine (Sus scrofa papillomavirus - SsPV1) [3]. 


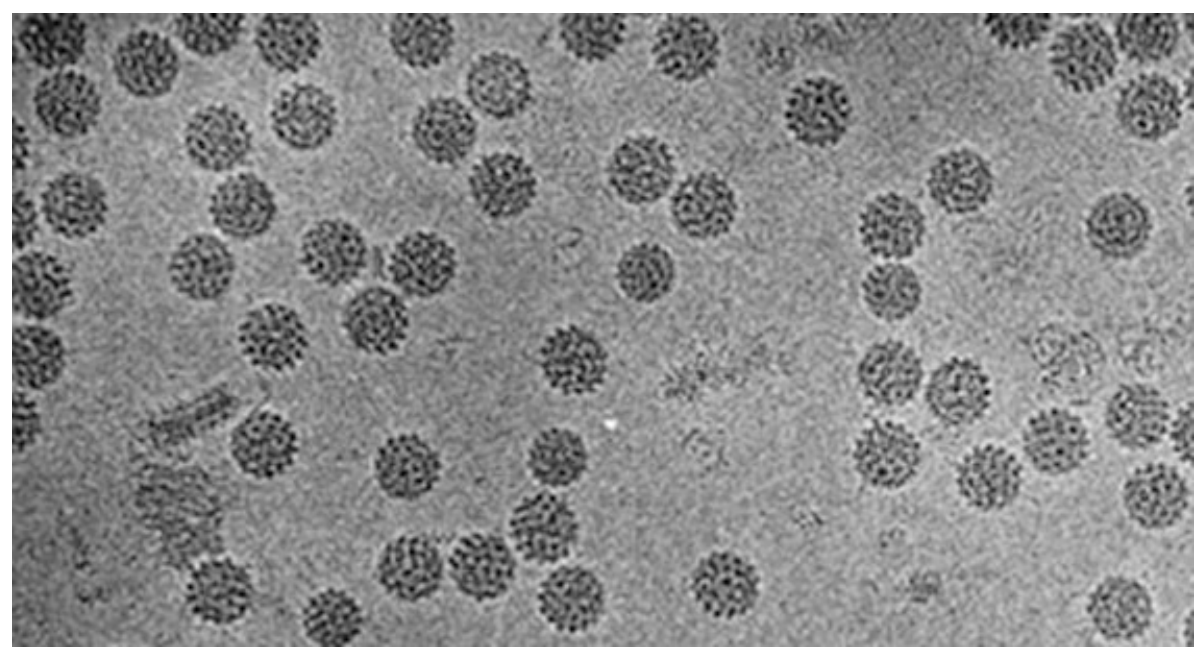

Figure 1. Electron micrograph of bovine papillomavirus type 1 virions (BPV1) (diameter of $55 \mathrm{~nm}$ ). Source: [1].

\section{Taxonomic classification of PVs}

Originally, PVs were grouped with the polyomaviruses in the family Papovaviridae, which was justified based on such shared traits as morphologically similar non-enveloped capsids and circular double-stranded DNA genomes. Because the genomes of both groups were later found to exhibit different sizes and organizations, as well as a low similarity between their nucleotide (nt) and aminoacid (aa) sequences, PVs are currently classified in the family Papillomaviridae $[4,5]$.

PVs are traditionally designated as "viral types". Each viral type represents a complete genome with the L1 gene nt sequence - which encodes the main capsid protein - exhibiting at least $10 \%$ dissimilarity compared with the same sequence from any other previously identified PV [5].

The classification of PVs into genera unites several phylogenetically related species that differ with respect to their biological properties, whereas classification based on species groups phylogenetically close viral types that also exhibit similar biological and pathological traits. In terms of nt sequence identity, these taxonomic relationships are expressed as follows: i) different genera exhibit less than $60 \%$ similarity in their L1 ORFs (open reading frames) and less than $23 \%$ to $43 \%$ when their full genomic sequences are compared; ii) different species within the same genus exhibit $60 \%$ to $70 \%$ similarity in their L1 ORFs (Table 1) [5].

Currently, the family Papillomaviridae contains at least 29 genera that include more than 200 PV types. The Greek alphabet is used to name the genera, which thus range from Alphapapillomavirus to Dyoiotapapillomavirus. Each species is designated according to the viral type that 


\begin{tabular}{cc}
\hline Taxonomic Level & L1 ORF Identity \\
\hline Genus & $<60 \%$ \\
\hline Species & $60-70 \%$ \\
\hline Viral Type & $71-89 \%$ \\
\hline
\end{tabular}

Table 1. Relationship between diverse taxonomic levels and the identity observed on the L1 ORF nt sequences. Source: [5].

best represents it, whereas the remaining PV types classified within a single species are named as virus strains (Table 2).

\begin{tabular}{|c|c|}
\hline Genera & Species \\
\hline \multirow{2}{*}{ Alphapapillomavirus } & Human Papillomavirus $2,6,7,10,16,18,26,32,34,53,54,61,90$ \\
\hline & Macaca mulata Papillomavirus 1 \\
\hline \multirow{2}{*}{ Betapapillomavirus } & Human Papillomavirus 5, 9, 49, 92, 96 \\
\hline & Macaca fascicularis Papillomavirus 2 \\
\hline Gammapapillomavirus & Human Papillomavirus 4, 48, 50, 60, 88, 101, 109, 112, 116, 121 \\
\hline \multirow{5}{*}{ Deltapapillomavirus } & Alces alces Papillomavirus 1 \\
\hline & Bos taurus Papillomavirus1 \\
\hline & Capreolus capreolus Papillomavirus 1 \\
\hline & Odocoileus virginianus Papillomavirus1 \\
\hline & Ovis aries Papillomavirus 1 \\
\hline Epsilonpapillomavirus & Bos taurus Papillomavirus 5 \\
\hline Zetapapillomavirus & Equus caballus Papillomavirus 1 \\
\hline Etapapillomavirus & Fringilla coelebs Papillomavirus \\
\hline Thetapapillomavirus & Psittacus erithacus Papillomavirus 1 \\
\hline lotapapillomavirus & Mastomys natalensis Papillomavirus 1 \\
\hline \multirow{2}{*}{ Kappapapillomavirus } & Oryctolagus cuniculus Papillomavirus 1 \\
\hline & Sylvilagus floridanus Papillomavirus 1 \\
\hline \multirow{3}{*}{ Lambdapapillomavirus } & Canis familiaris Papillomavirus 1 and 6 \\
\hline & Felis domesticus Papillomavirus 1 \\
\hline & Procyon lotor Papillomavirus 1 \\
\hline Mupapillomavirus & Human Papillomavirus 1 and 63 \\
\hline Nupapillomavirus & Human papillomavirus 41 \\
\hline Xipapillomavirus & Bos taurus Papillomavirus 3 \\
\hline \multirow{2}{*}{ Pipapillomavirus } & Mesocricetus auratus Papillomavirus 1 \\
\hline & Micromys minutus Papillomavirus 1 \\
\hline Rhopapillomavirus & Trichechus manatus latirostris Papillomavirus 1 \\
\hline
\end{tabular}




\begin{tabular}{cc}
\hline Genera & Species \\
\hline Sigmapapillomavirus & Erethizon dorsatum Papillomavirus 1 \\
\hline Taupapillomavirus & Canis familiaris Papillomavirus 2 \\
\hline Upsilonpapillomavirus & Tursiops truncatus Papillomavirus 1 and 2 \\
\hline Phipapillomavirus & Capra hircus Papillomavirus 1 \\
\hline Chipapillomavirus & Canis familiaris Papillomavirus 3 and 4 \\
\hline Psipapillomavirus & Rousettus aegyptiacus Papillomavirus 1 \\
\hline Omegapapillomavirus & Ursus maritimus Papillomavirus 1 \\
\hline Dyodeltapapillomavirus & Sus scrofa Papillomavirus 1 \\
\hline Dyoepsilonpapillomavirus & Francolinus leucoscepus Papillomavirus 1 \\
\hline Dyozetapapillomavirus & Caretta caretta Papillomavirus 1 \\
\hline Dyoetapapillomavirus & Erinaceus europaeus Papillomavirus 1 \\
\hline Dyothetapapillomavirus & Felis domesticus Papillomavirus 2 \\
\hline Dyoiotapapillomavirus & Equus caballus Papillomavirus 2 \\
\hline
\end{tabular}

Table 2. Classification of Papillomaviridae family. Source: [3].

PVs isolated from vertebrates are classified into 24 genera, whereas viral species that occur exclusively in birds and reptiles are grouped into three genera and one genus, respectively. The taxonomic nomenclature of animal PV types is based on the scientific name of their hosts according to the genus and species. For example, FdPV1 is the name given to PV of the domestic cat (Felis domesticus) type 1 [3]. An exception occurs in the case of the bovine papillomavirus, which was named Bos taurus papillomavirus but by consensus is usually referred to as BPV. Table 3 describes the genera and species of PVs identified in various species of domestic animals.

Because PVs are not amenable to isolation using classic cell culture techniques and do not induce a strong humoral immune response in their hosts, the taxonomic terms "strain" and "serotype" were not originally applied to this virus family. Consequently, the family classification is based on the similarities between nt sequences and a limited number of biological and medical properties [5,6].

\section{Genomic organization}

In the 1970s, the cloning of PVs genomes contributed substantially to the study of their biological and biochemical properties. Sequencing of the cloned genomes allowed the identification of different ORFs as probable viral genes [7].

The genomic organization of the various PVs is notably similar. A common feature of PVs is that all of the ORFs are contained on a single strand of the viral DNA. Therefore, only one of 


\begin{tabular}{|c|c|c|}
\hline Genera & Species & Viral Strains \\
\hline \multirow{4}{*}{ Deltapapillomavirus } & \multirow{2}{*}{ Bos taurus Papillomavirus 1} & Bos taurus Papillomavirus 1 \\
\hline & & Bos taurus Papillomavirus 2 \\
\hline & \multirow{2}{*}{ Ovis aries Papillomavirus 1} & Ovis aries Papillomavirus 1 \\
\hline & & Ovis aries Papillomavirus 2 \\
\hline \multirow{2}{*}{ Epsilonpapillomavirus } & \multirow{2}{*}{ Bos taurus Papillomavirus 5} & Bos taurus Papillomavirus 5 \\
\hline & & Bos taurus Papillomavirus 8 \\
\hline Zetapapillomavirus & Equus caballus Papillomavirus 1 & Equus caballus Papillomavirus 1 \\
\hline \multirow{3}{*}{ Lambdapapilloamvirus } & Canis familiaris Papillomavirus 1 & Canis familiaris Papillomavirus 1 \\
\hline & Canis familiaris Papillomavirus 6 & Canis familiaris Papillomavirus 6 \\
\hline & Felis domesticus Papillomavirus 1 & Felis domesticus Papillomavirus 1 \\
\hline \multirow{7}{*}{ Xipapillomavirus } & \multirow{7}{*}{ Bos taurus Papillomavirus 3} & Bos taurus Papillomavirus 3 \\
\hline & & Bos taurus Papillomavirus 4 \\
\hline & & Bos taurus Papillomavirus 6 \\
\hline & & Bos taurus Papillomavirus 9 \\
\hline & & Bos taurus Papillomavirus 10 \\
\hline & & Bos taurus Papillomavirus 11 \\
\hline & & Bos taurus Papillomavirus 12 \\
\hline \multirow{2}{*}{ Taupapillomavirus } & \multirow{2}{*}{ Canis familiaris Papillomavirus 2} & Canis familiaris Papillomavirus 2 \\
\hline & & Canis familiaris Papillomavirus 7 \\
\hline Phipapillomavirus & Capra hircus Papillomavirus 1 & Capra hircus Papillomavirus 1 \\
\hline \multirow{3}{*}{ Chipapillomavirus } & \multirow{2}{*}{ Canis familiaris Papillomavirus 3} & Canis familiaris Papillomavirus 3 \\
\hline & & Canis familiaris Papillomavirus 5 \\
\hline & Canis familiaris Papillomavirus 4 & Canis familiaris Papillomavirus 4 \\
\hline Dyodeltapapillomavirus & Sus scrofa Papillomavirus 1 & Sus scrofa Papillomavirus 1 \\
\hline Dyothetapapillomavirus & Felis domesticus Papillomavirus 2 & Felis domesticus Papillomavirus 2 \\
\hline Dyoiotapapillomavirus & Equus caballus Papillomavirus 2 & Equus caballus Papillomavirus 2 \\
\hline- & - & Bos taurus Papillomavirus 7 \\
\hline
\end{tabular}

Table 3. Papillomavirus species that infect domestic animals. Source: Adapted from [3].

the DNA strands serves as a template for transcription. The coding strand might exhibit up to 10 ORFs, which are classified according to the cell differentiation stage when they are expressed by means of the letters $\mathrm{E}$ (early) and L (late). The early genomic segment (E) comprises up to eight ORFs, which are expressed in epithelial cells in the early stages of maturation.The 
late segment (L) usually contains two ORFs that are expressed in differentiated keratinocytes. A third region without ORFs has been identified in all PV genomes and is named the LCR (long control region) or URR (upstream regulatory region).This region contains the origin of replication and elements that control transcription (Figure 2) [1].

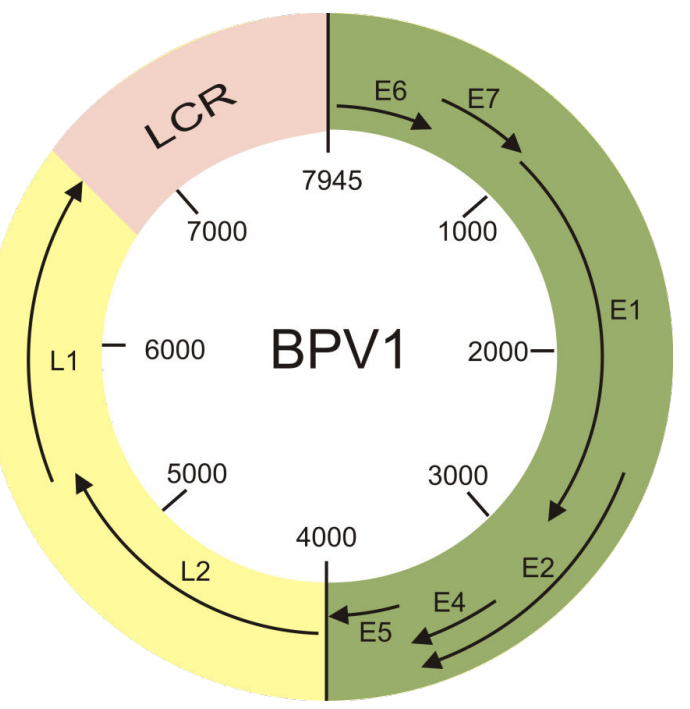

Figure 2. Schematic representation of genome of bovine papillomavirus type 1 (BPV1).

Expression of the six most common non-structural and regulatory proteins (E1, E2, E4, E5, E6, and E7), which are encoded by the early viral genome region, occurs in basal cells or during the intermediate stages of maturation. The expression of the two viral structural proteins (L1 and L2) encoded by the late genomic segment occurs in keratinocytes in the final stage of maturation [8].

\section{Viral proteins}

\subsection{Proteins E1 and E2}

Protein E1 is encoded by the largest ORF found in the early genomic segment of PVs. Significant homology among the different PVs has been found upon comparison of the amino acid sequences inferred for the proteins that are encoded by the E1 gene [9].

Together with viral protein E2, protein E1 recognizes the origin of replication and represents the central factor of PV replication. It is indispensable for the initiation of viral DNA replication. In addition to this main function, E1 participates in the recruitment of host cell replication proteins and exhibits intrinsic ATPase/helicase activity, which induces relaxation of the DNA coiling at the origin of replication and during the progression of the replication fork [9]. 
Transformation studies using BPV1 have shown that the presence of an intact E1 ORF is crucial for the maintenance of viral genome stability in cells through the presence of multiple genomic copies in episomal form $[10,11,12]$.

However, the interaction between protein E1 and the origin of replication exhibits low specificity. Specific and efficient recognition of the origin of replication occurs exclusively through the cooperative binding of proteins E1 and E2 to sites adjacent to the origin of replication. Therefore, protein E2 participates in this mechanism as an aggregation factor that promotes the recruitment of helicase E1 to the origin of replication [13].

The BPV1 E2 ORF encodes a protein that comprise the central viral regulatory system and thus control genetic expression and viral replication. Protein E2 also modulates the transcription of the early viral promoters through its binding sites [14]. In addition, E2 participates in the maintenance of the viral genome in its episomal form by promoting binding between these genomes and mitotic chromosomes during cell division $[15,16]$.

\subsection{Protein E4}

The non-structural protein E4 occurs abundantly in the cytoplasm of the differentiated keratinocytes of papillomas. Therefore, although the gene that encodes this protein is located in the early viral genome region, E4 is produced later in the differentiation process. The E4 protein of HPV16 has also been associated with the collapse of cytokeratin filaments, which thus suggests an auxiliary function in the process of viral exit from cells [1].

\subsection{Proteins E5, E6 and E7}

In humans, the oncoproteins E5, E6, and E7 encoded by the genomes of certain HPVs, represent the primary viral factors related to the onset and progression of cervical cancer. These genetic products are able to override the negative regulation of cell growth that is mediated by host cell proteins. In addition, it is believed that these viral oncoproteins promote the genomic instability observed in HPV-related cancers [17].

Binding with proteins of the retinoblastoma family is the main mechanism by which protein E7 contributes to the escape of infected cells from the negative regulatory mechanisms of cell growth. In the case of HPV, protein E7 interacts with these cellular factors and targets them for degradation [18]. The result of such binding and degradation is the release and activation of E2F transcription factors that regulate the expression of genes during $S$ phase of the cell cycle. Efficient interaction between E7 and these factors triggers a compensatory inhibition of cell growth and apoptosis that is mediated by the p53 tumor suppressor protein-dependent pathway [17].

The targeting of protein p53 for degradation by viral protein E6 in high-risk HPVs eliminates the inhibition of cell growth in both undifferentiated and differentiated cells [17]. The actions of the viral proteins E6 and E7 to abrogate these regulatory factors of the cell cycle allow infected cells undergoing differentiation to remain in S phase. As a result, many cell cycle checkpoints are abrogated. Consequently, an accumulation of mutations and progression into cancer occurs in cells that are persistently infected by these viruses [19]. 
Most of the tumors of cattle affected by enzootic hematuria express the BPV2 oncoprotein E5 $[20,21,22]$. The onset of cellular transformation that is triggered by E5 might occur mainly through its interaction with and activation of the platelet-derived growth factor (PDGF) $\beta$ receptor. Thus, a mitogenic response is induced even in the absence of PDGF [23,24].

\subsection{Proteins L1 and L2}

The viral capsid consists of the two structural proteins L1 (ca. $55 \mathrm{kDa}$ ) and L2 (ca. $70 \mathrm{kDa})$, being L1 the major capsid protein and representing approximately $80 \%$ of the total virus protein [25]. Virus-like particles (VLPs) can be produced using prokaryotic and eukaryotic systems to express combination of L1 and L2 or L1 alone [26,27]. Although L2 is not needed for viral assembly, it is incorporated in the VLPs when it is co-expressed with L1. Under cryoelectron microscopy, the morphology of the VLPs that contain only L1 appear identical to that of intact viral particles (Figure 3) [28]. The epitopes that induce the production of neutralizing antibodies are principally found on L1 but might also be present on L2 (Table 4) [29].

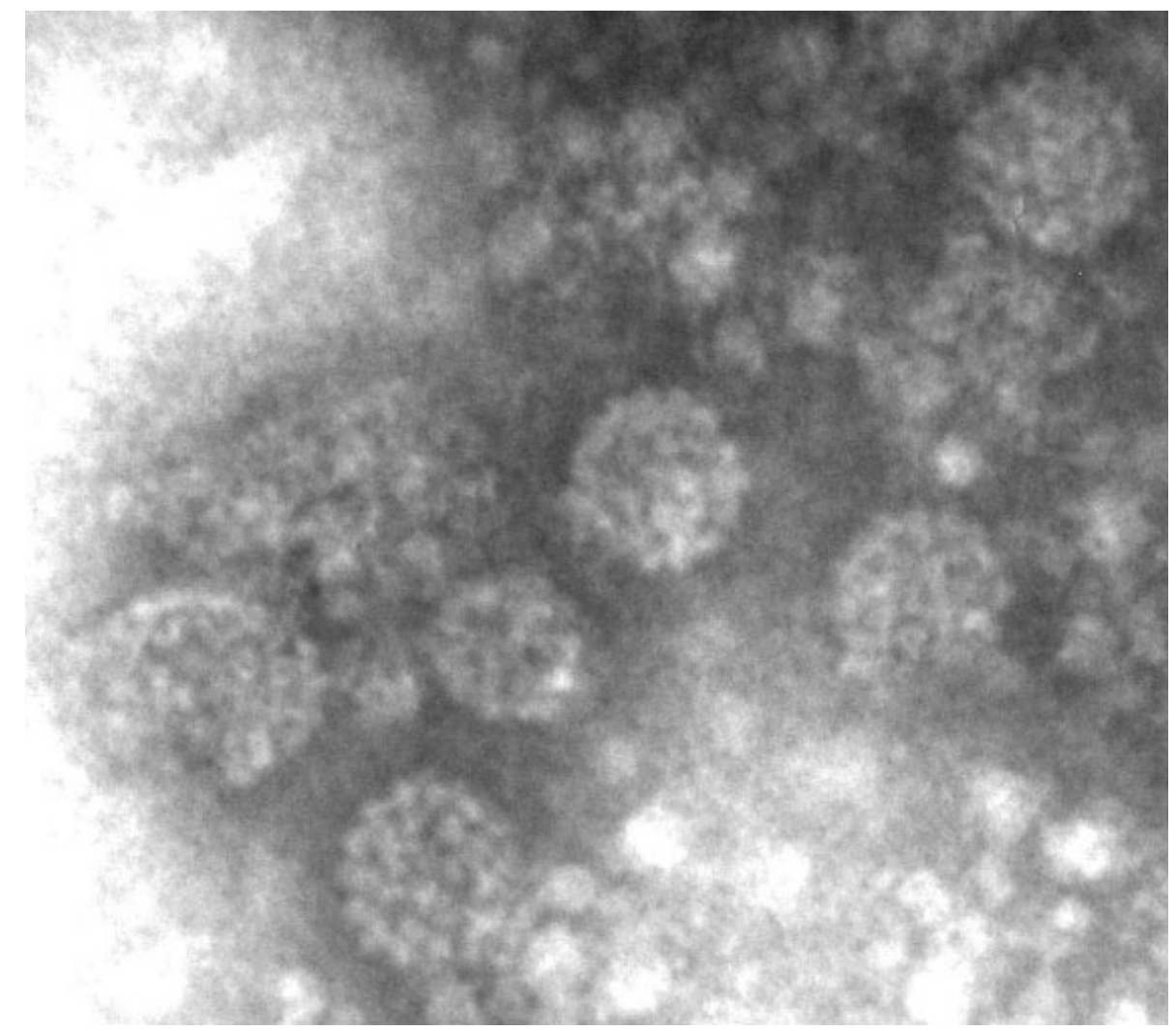

Figure 3. Electron micrograph of VLP sproduced through expression of BPV2 L1. 


\begin{tabular}{|c|c|c|}
\hline Viral Proteins & $\begin{array}{l}\text { Approximate size } \\
\qquad(\mathrm{kDa})\end{array}$ & Function / activity \\
\hline E1 & 68.1 & recognition of origin of replication / helicase activity \\
\hline E2 & 34.3 & $\begin{array}{l}\text { recruitment of E1 to the origin of replication / modulation of the } \\
\text { transcription of the early viral promoters }\end{array}$ \\
\hline E4 & 12.5 & presumed auxiliary function in the virion exit from infected cells \\
\hline E5 & 5.2 & $\begin{array}{c}\text { interacts with and activates the platelet-derived growth factor (PDGF) } \beta \\
\text { receptor }\end{array}$ \\
\hline E6 & 15.8 & targets p53 tumor suppressor protein \\
\hline E7 & 13.6 & binds to proteins of the retinoblastoma family \\
\hline L1 & 55.5 & component of the viral capsid \\
\hline L2 & 50.5 & component of the viral capsid \\
\hline
\end{tabular}

Table 4. Viral proteins and their functions.

\section{Clinical conditions in cattle}

Infections by different BPV types are related to several clinical conditions in cattle. The occurrence of the benign skin tumors that characterize cutaneous papillomatosis might be found in several areas of the animals' bodies. Depending on the extent of lesions, the development of the animals might be affected, they might become predisposed to secondary infections and/or infestations, and their hidescan be damaged. These possibilities are a few of the potential consequences that might result in economic losses for the beef and, even more so, dairy industries. Papillomas affecting the udders and teats of lactating cows cause difficulties with feeding calves and manual and mechanical milking, whereas secondary bacterial infections predispose the animals to clinical and/or subclinical ascending mastitis [30].

The interaction between specific BPV types and prolonged bracken (Pteridium aquilinum) intake has been suggested as the cause of enzootic hematuria and upper gastrointestinal tract cancers in cattle. With regard to enzootic hematuria, it is believed that latent or subclinical infections with BPV1 or BPV2 occur first in the bladder mucosa. Because the bladder represents the main target of bracken toxins, once the virus is established, infection might be reactivated, which might induce neoplasia through the immunosuppressant and carcinogenic chemical compounds present in bracken, which results in progression to malignancy [31].

Although the incidence of such tumors varies among cattle raised on bracken-infested pastures, it might be higher than $90 \%$ among adult animals [31,32].

With regard to gastrointestinal tract tumors, the immunosuppression associated with bracken intake is defining for the persistence of BPV4-induced papillomas, which might progress into 
malignant carcinomas under the influence of the carcinogenic elements present in bracken [33,34,35].

Therefore, although infection by these BPVs plays a central role in the pathogenesis of these cattle neoplasias, the presence of environmental and biological cofactors is essential for the development of such lesions $[22,36]$.

\section{Diversity of BPVs}

Although the genomic sequences of approximately 150 HPV types have already been characterized, at the beginning of the 1980s only six BPV types (BPV1 to 6) had been identified from cases of bovine cutaneous papillomatosis and cancer [37-42].

Studies performed from the beginning of the 2000s onward to investigate the actual diversity of BPVs have indicated the existence of many BPV types, which is similar to observations made regarding the human virus. The first such study employed the generic primer pair FAP59/FAP64 on swabs of healthy skin from 19 species of vertebrates. In six of the 10 analyzed bovines that did not exhibit any clinical sign compatible with BPV infection, one or two putative new BPV types were detected. These putative new viral types were named BAA1 through BAA5 [43].

Subsequently, a study aimed at establishing the prevalence of BPV in teat papillomas and teat healthy skin used the primer pairs FAP59/FAP64 and MY09/MY11 to analyze 15 teat papillomas and 122 swabs of teat healthy skin on cattle from five Japanese prefectures [44]. That study found four previously characterized BPV types (BPV1, 3, 5, and 6), two of the previously identified putative new BPV types (BAA1 and 5), and 11 additional putative new types (named BAPV1 through 10 and BAPV11MY) among the 39 BPV-positive samples. Nevertheless, the putative new types BAA1 and BAPV7 through 10 were detected only in samples of healthy skin. In addition, during one outbreak of mammary papillomatosis that occurred in Japan and affected 560 heifers, the presence of BPV6 was confirmed in the majority of the 16 analyzed samples [45]. The previously described putative new types BAA5 and BAPV1 were also identified in these animals.

Although cutaneous papillomatosis poses a serious sanitary problem in beef and, even more so, dairy cattle, studies aimed at identifying the BPV types involved in the occurrence of skin lesions in Brazilian cattle are only sporadically performed. Recently, the detection of BPV1, 2, 6 , and 8 in papillomas of cattle from the state of Parana was accomplished using generic FAP primers $[46,47]$. In another study, the identification of four previously undescribed putative new BPV types, named BPV/BR-UEL 2 through 5, pointed to the occurrence of considerable viral diversity among Brazilian cattle [48]. The genetic characterization of one of these new BPV types, namely, BPV/BR-UEL2, through sequencing of the full L1 gene, confirmed that it belongs to the genus Xipapillomavirus [49] (Figure 4). 


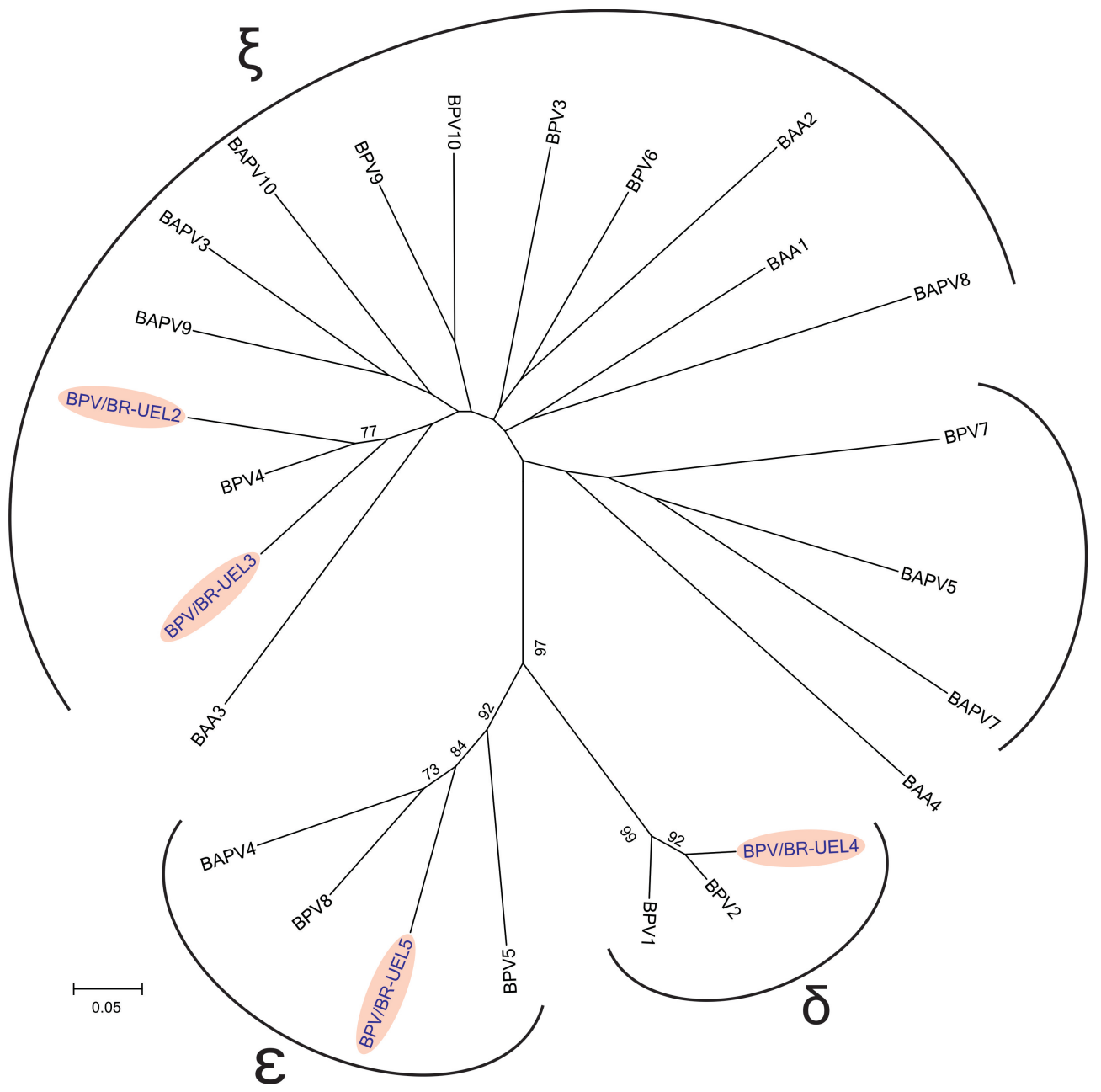

Figure 4. Phylogenetic reconstruction based on L1 ORF partial nucleotide sequences (FAP amplicons) demonstrating the classification suggested for the putative new BPV types into the genera Deltapapillomavirus ( $\delta$ ), Epsilonpapillomavirus $(\varepsilon)$, Xipapillomavirus $(\xi)$, and a yet unnamed genus that includes BPV7. The numbers at the internal nodes represent the bootstrap support values determined for 1000 replicates. The BPV/BR-UEL2, 3, 4, and 5 types are indicated by shading. Source: [48].

\section{New BPV types}

Recently, complementary analysis of several putative new BPV types through sequencing of the full viral genomes allowed the characterization of these new viral types [3]. The first such new type to be characterized was BPV7, which was initially named BAPV6. Because the nt 
sequence of the BPV7 L1 ORF is more closely related to PVs of the genera Betapapillomavirus, Gammapapillomavirus, and Pipapillomavirus, which include viruses causing skin lesions in human beings and the mucosa of hamsters, this new BPV type constitutes a new and yet unnamed genus [50].

The second recently described BPV type is BPV8, formerly known as BAPV2, which was identified in Japan. The description of this new viral type was performed together with the description of a variant named BPV8-EB, which was detected in a case of cutaneous papillomatosis in a European bison born in Italy [51]. The high degree of similarity observed between the L1 ORF sequences of BPV8 and BPV5 (75\%), as well as the results of the phylogenetic analysis, were the basis for classifying this new viral type in the genus Epsilonpapillomavirus. In addition, the genomic structures of the early and late regions of these two different members of the genus were almost identical. The only difference exhibited between them was in the E4 ORF, which is present in BPV8 but absent in BPV5.

Recently, two BPV types, namely, BPV9 and 10, were identified from teat papillomas [52]. These new viral types were initially designated BAPV1 and BAA5 $[43,44]$. Phylogenetic analysis and the greater similarity of the L1 ORFs with BPV3 (74.2\% and 71.2\%, respectively) allowed the classification of these two new isolates in the genus Xipapillomavirus [52].

Hatama [53] assessed the viral genotypes present in 167 skin warts in Japanese herds through polymerase chain reaction (PCR), cloning, and sequencing. A total of 124 of the assessed lesions tested positive for BPV using PCR. Three putative new BPV types, and eight previously described BPV types (BPV1, 2, 3, 4, 5, 6, 9, and 10) were identified in the partial sequences obtained from sequencing the PCR products. The characterization of the full sequence of one of the new BPV types (BPV11) and the comparison of its L1 gene nt sequence to other members of this viral family allowed its classification in the genus Xipapillomavirus [53].

The complete genome sequence of an isolate identified from an epithelial tongue lesion in a Japanese bovine was recently obtained, and this isolate was named BPV12 [54]. Comparison of the BPV12 L1 gene nt sequence to other viral types isolated from cattle suggested that it should also be classified in the genus Xipapillomavirus.

Recently, the sequencing of the complete genome of the putative new viral type BPV-BR-UEL4, which was isolated from a skin papilloma on a cow from a herd in southern Brazil,was performed by subjecting the viral genome to rolling circle amplification (RCA), PCR, the subsequent cloning of two long amplicons, and sequencing by means of primer walking. Phylogenetic analysis based on the L1 ORF nt sequences of 45 PVs distributed among 17 genera, including the previously sequenced BPV types and PVs identified from different artiodactyl species, showed that the new viral type, named BPV13, belongs to the genus Deltapapillomavirus, which is generally dominated by artiodactyl PVs and also includes BPV1 and 2 (Figure 5). As previously reported for BPV1 and 2, the putative E7 protein of BPV13 does not contain a retinoblastoma tumor suppressor-binding domain. Additionally, the BPV13 E5 ORF also encodes a small transforming protein (Figure 6) [55]. The combination of these two different biological aspects has been recognized as a distinct marker for fibropapilloma development. This pathogenic mechanism appears to be unique among delta-PVs [56]. 


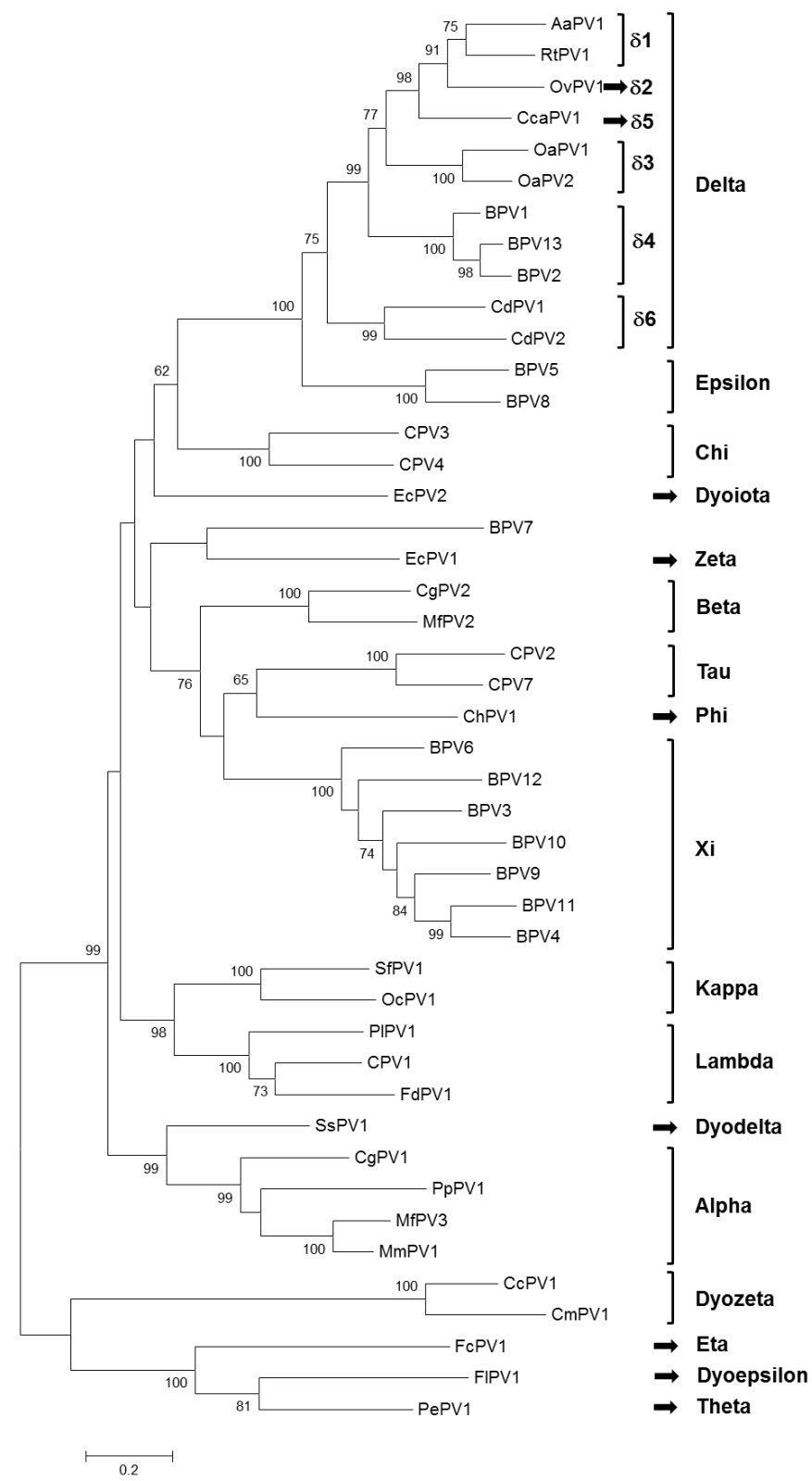

Figure 5. Phylogenetic tree based on L1 ORF nt sequences. In addition to 14 genera where animal PVs are classified, the genera Deltapapillomavirus, Epsilonpapillomavirus, and Xipapillomavirus, which contain BPVs, are indicated in the tree. Additionally, the six species classified within the Deltapapillomavirus genus are shown. The numbers at the internal nodes represent the bootstrap support values determined in 1000 replications. Source: [55] 


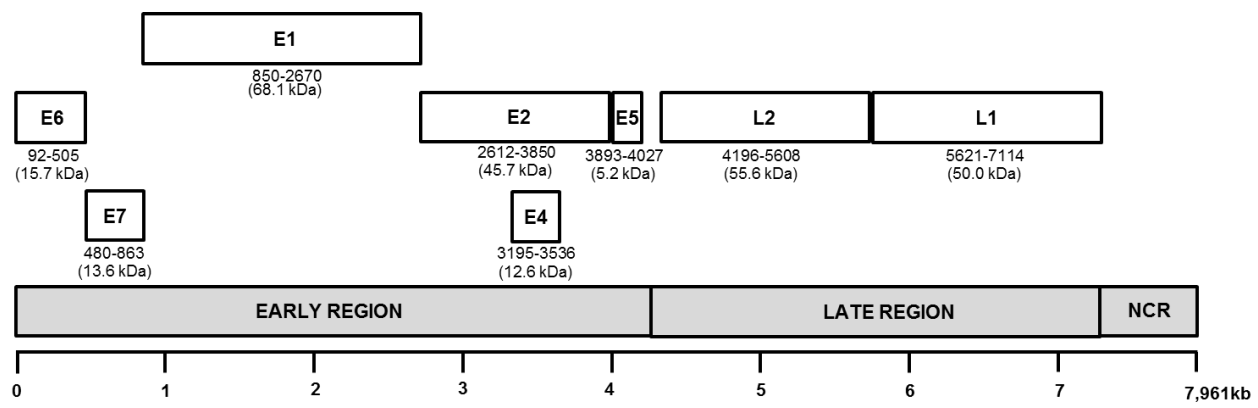

Figure 6. A diagram of the genomic organisation of BPV13. The three main regions characteristic of PV genomes are shown as grey rectangles above the ruler. The viral genome is represented as linear, and ORFs are shown as white rectangles. The numbers below each ORF indicate the nt positions of the start to stop codons and the corresponding molecular mass (in parentheses) for each putative viral protein. Source: [55].

\section{Co-infections and heterologous infections}

In Brazil, the association between BPV infection and the occurrence of cutaneous papillomatosis, enzootic hematuria, and upper gastrointestinal neoplasias has been confirmed in cattle [46,48,57-59]. Previous studies have found BPV in tissues other than the skin epithelium. Thus, BPV1, 2, and 4 have been identified in the embryos and female reproductive tissues of infected cows [60-63]. Similarly, BPV DNA has been detected in samples of blood, milk, urine, seminal fluid, and spermatozoa from infected cattle. These findings point to the possible participation of these fluids and cell types in BPV transmission [64].

In addition, other studies have shown the occurrence of multiple infections in cattle exhibiting several cutaneous papillomas that are caused by different BPV types and the possibility of viral co-infections in single lesions [65-68]. Additionally, the presence of several BPV types in single lesions is similar to the situation in human skin, where co-infection by more than 10 viral types is frequently detected [69].

Each papillomavirus is known to exhibit specificity for a single animal host species in which it replicates productively. However, only a few viral types are also able to infect a second animal species. In such cases, non-productive infections, that is, infections without the production of infective virions, are the result [1]. This type of infection is the case for the equine sarcoid, which can be defined as a fibroblastic locally invasive skin tumor. Sarcoid is the most frequent neoplasia affecting equine species, and it represents the best-known example of heterologous PV infection because it is caused by BPV1 and 2 [70]. In addition to horses, donkeys, and mules, skin lesions caused by these viral types have also been described in zebras and buffaloes [71,72]. Another example of heterologous PV infection is provided by the detection of DNA from FeSarPV (feline sarcoid-associated papillomavirus), a putative new PV type that was initially identified in feline sarcoids with non-productive infections, in fibropapillomas and skin samples from cattle with dermatitis [73-75]. The recent detection of FeSarPV in biological samples from cattle strengthens the hypothesis that cattle might be the natural host of this virus [73]. 


\section{Vaccines against BPV}

Immunity against BPV is considered to be type-specific, and the immune status of the infected animals is considered to be the crucial factor for clinical progression. Whereas humoral immunity prevents new infections, cellular immunity (possibly mediated by $\mathrm{T}$ lymphocytes) is associated with the spontaneous and immune-mediated regression of established lesions [76].

The finding that epitopes that induce the production of neutralizing antibodies are present in the structural proteins L1 and L2 explains the success of the use of these proteins in the production of vaccines [34].

The recent availability of VLP-based immunogens against HPV that are able to protect mainly against infection by HPV16 and 18 has allowed the development of the first vaccine against one of the main human neoplasias, i.e., cervical cancer [77]. The data that have been collected since the implementation of the HPV vaccine are quite encouraging, and these vaccines seem to be highly efficient $[78,79]$.

In addition, preventive vaccines have been developed for cattle that are mainly against BPV2 and 4 . These viral types were selected because they represent the cutaneous and mucous BPVs, respectively, and are associated with the development of cancer in cattle [80]. A vaccine prepared with the BPV2 L1 capsid protein produced as a beta-galactosidase fusion protein in Escherichia coli induced the production of neutralizing antibodies and was able to prevent infection [81]. A similar effect was achieved using an E. coli derived BVP1 L1 protein, which protected calves against post-vaccine challenge with a homologous virus [82].

VLPs produced from the L1 or L1 and L2 genes from BPV4 have also proven to be highly immunogenic and produce powerful prophylactic vaccines. The prevention of infection during challenge with BPV4 through vaccination with L1 VLPs has shown that L1 promotes the production of neutralizing antibodies [34]. Vaccination with VLPs produced from BPV4 L1 and L2 proteins in insect cells also efficiently prevented the development of experimentally induced papillomas [83].

Because BPV does not grow in conventional cell cultures for the production of killed or attenuated live vaccines, protein expression systems, such as yeast and insect cells, have been used to produce VLP vaccines. However, the use of these systems is expensive. Recently, as has been described for other papillomaviruses (e.g., HPV16), a candidate vaccine against BPV1 consisting of L1 VLPs produced in planta elicited a strong and specific immune response, which demonstrated its potential as a future vaccine that could be produced at a lower cost [84].

Because the viral life cycle and the progression from benign to malignant lesion are similar in humans and animals, animal PVs and their natural hosts have represented good models for the study of HPV [30,85]. In addition, animal PVs, particularly BPV1 and 4, SfPV1, and CPV1, have also served as models for vaccines against PVs, and observation of the induction of protective immunity through the use of VLP-based vaccines in their corresponding host species has opened the way for the implementation of VLPs in HPV vaccines [86,87]. 
Currently, immunization through the use of L2 protein peptides has been suggested as an alternative to the use of VLP-based HPV vaccines. Curiously, residues at the $\mathrm{N}$ terminus of the L2 viral protein appear to represent a cross-neutralizing epitope capable of eliciting a broad-spectrum protection against many different viral types [87]. Once more, vaccination of both cattle and rabbits with L2-based vaccines has been highly protective against challenge with infectious virus [88,89], which confirms the great potential of L2 vaccines in preventing HPV infections.

\section{Conclusion}

BPV infection is associated with cutaneous papillomatosis, enzootic hematuria and upper gastrointestinal tract cancers in cattle. Although approximately $150 \mathrm{HPV}$ types have already been characterized, only $13 \mathrm{BPV}$ types had their genomes sequenced. However, in accordance with diversity observed from HPVs, the identification of numerous putative new BPV types through partial L1 gene sequences have pointed to the occurrence of a similar diversity among BPVs. Historically, together with a few animal PVs, BPVs and cattle have represented good models for the study of HPV and vaccines against this important human pathogen, fact that opened the way for the implementation of VLPs in HPV vaccines. The demonstration of protective effect of L2-based vaccines in this animal species reinforces the possibility of the future use of L2 protein peptides as an alternative vaccine to prevent HPV infections.

\section{Acknowledgements}

This work was supported by the Brazilian funding agencies CAPES, CNPq, FINEP and Fundação Araucaria (FAP/PR). A.A.A. and A.F.A. are supported by research fellowships from CNPq.

\section{Author details}

Michele Lunardi ${ }^{1}$, Amauri Alcindo Alfieri ${ }^{2 *}$, Rodrigo Alejandro Arellano Otonel ${ }^{2}$ and Alice Fernandes Alfieri ${ }^{2}$

*Address all correspondence to: alfieri@uel.br

1 Laboratory of Veterinary Microbiology, Veterinary Teaching Hospital, Universidade de Cuiaba, Cuiaba, MT, Brazil

2 Laboratory of Animal Virology, Department of Veterinary Preventive Medicine, Universidade Estadual de Londrina, Londrina, PR, Brazil 


\section{References}

[1] Howley PM, Lowy DR. Papillomaviruses. In: Knipe DM, Howley PM. (Eds.) Fields' Virology, Philadelphia: Lippincott Williams and Wilkins; 2007. p 2300-2354.

[2] Shope RE, Hurst EW. Infectious Papillomatosis of Rabbits; with a Note on the Histopathology. The Journal of Experimental Medicine 1933;58 607-624.

[3] Bernard HU, Burk RD, Chen Z, van Doorslaer K, Hausen H, de Villiers EM. Classification of Papillomaviruses (PVs) Based on 189 PV Types and Proposal of Taxonomic Amendments. Virology 2010;401 70-79

[4] van Regenmortel MHV, Fauquet CM, Bishop DHL, Calisher CH, Carsten EB, Estes MK, Lemon SM, Maniloff J, Mayo MA, Mcgeoch DJ, Pringle CR, Wickner RB. Virus Taxonomy. Seventh Report of the International Committee for the Taxonomy of Viruses. New York, San Diego: Academic Press; 2002.

[5] de Villiers EM, Fauquet C, Broker TR, Bernard HU, Zur Hausen H. Classification of Papillomaviruses. Virology 2004;324 17-27.

[6] Fauquet CM, Mayo MA, Maniloff J, Desselberger U, Ball LA. Virus Taxonomy. The Eighth Report of the International Committee on Taxonomy of Viruses. Family Papillomaviridae. Elsevier; 2005.

[7] Danos O, Katinka M, Yaniv M. Human Papillomavirus la Complete DNA Sequence: A Novel type of Genome Organization Among Papovaviridae. The EMBO Journal 1982;1 231-236.

[8] Zheng ZM, Baker CC. Papillomavirus Genome Structure, Expression, and Post-transcriptional Regulation. Frontiers in Bioscience 2006;11 2286-2302.

[9] Wilson VG, West M, Woytek K, Rangasamy D. Papillomavirus E1 Proteins: Form, Function, and Features. Virus Genes 2002;24 275-290.

[10] Sarver N, Rabson MS, Yang YC, Byrne JC, Howley PM. Localization and Analysis of Bovine Papillomavirus Type 1 Transforming Functions. Journal of Virology 1984;52 377-388.

[11] Lusky M, Botchan MR. Genetic analysis of Bovine Papillomavirus Type 1 Trans-acting Replication Factors. Journal of Virology 1985;53 955-965.

[12] Rabson MS, Yee C, Yang YC, Howley PM. Bovine Papillomavirus Type 13' Early Region Transformation and Plasmid Maintenance Functions. Journal of Virology 1986;60 626-634.

[13] Sanders CM, Stenlun, A. Mechanism and Requirements for Bovine Papillomavirus, Type 1, E1 Initiator Complex Assembly Promoted by the E2 Transcription Factor Bound to Distal Sites. The Journal of Biological Chemistry 2001;276 23689-23699. 
[14] Spalholz B, Yang Y, Howley P. Transactivation of a Bovine Papilloma Virus Transcriptional Regulatory Element by the E2 Gene Product. Cell 1985;42 183-191.

[15] Ilves I, Kivi S, Ustav M. Long-term Episomal Maintenance of Bovine Papillomavirus Type 1 Plasmids is Determined by Attachment to Host Chromosomes, which is Mediated by the Viral E2 Protein and its Binding Sites. Journal of Virology 1999;73 4404-4412.

[16] Lehman CW, Botchan MR. Segregation of Viral Plasmids Depends on Tethering to Chromosomes and is Regulated by Phosphorylation. Proceedings of the National Academy of Sciences of the United States of America 1998;95 4338-4343.

[17] Moody CA, Laimins LA. Human Papillomavirus Oncoproteins: Pathways to Transformation. Nature Reviews. Cancer 2010;10 550-560.

[18] Dyson N, Howley PM, Munger K, Harlow E. The Human Papilloma Virus16 E7 Oncoprotein is Able to Bind to the Retinoblastoma Gene Product. Science 1989;243 934937.

[19] Duensing S, Munger K. Mechanisms of Genomic Instability in Human Cancer: Insights from Studies with Human Papillomavirus Oncoproteins. International Journal of Cancer 2004;109 157-162.

[20] Campo MS, Jarrett WFH, Barron RJ, O'neil BW, Smith KT. Association of Bovine Papillomavirus Type 2 and Bracken Fern with Bladder Cancer in Cattle. Cancer Research 1992;53 6898-6904.

[21] Borzacchiello G, Iovane G, Marcante ML, Poggiali F, Roperto F, Roperto S, Venuti A. Presence of Bovine Papillomavirus Type 2 DNA and Expression of the Viral Oncoprotein E5 in Naturally Occurring Urinary Bladder Tumors in Cows. Journal of General Virology 2003;84 2921-2926.

[22] Roperto S, Brun R, Paolini F, Urraro C, Russo V, Borzacchiello G, Pagnini U, Raso C, Rizzo C, Roperto F, Venuti A. Detection of Bovine Papillomavirus Type 2 (BPV2) in the Peripheral Blood of Cattle with Urinary Bladder Tumors: Possible Biological Role. Journal of General Virology 2008;89 3027-3033.

[23] DiMaio D, Mattoon D. Mechanisms of Cell Transformation by Papillomavirus E5 Proteins. Oncogene 2001;20 7866-7873.

[24] Borzacchiello G, Russo V, Gentile F, Roperto F, Venuti A, Nitsch L, Campo MS, Roperto S. Bovine Papillomavirus E5 Oncoprotein Binds to the Activated Form of the Platelet-derived Growth Factor Beta Receptor in Naturally Occurring Bovine Urinary Bladder Tumours. Oncogene 2006;25 1251-60.

[25] Favre M. Structural Polypeptides of Rabbit, Bovine, and Human Papillomaviruses. Journal of Virology 1975;15 1239-1247. 
[26] Rose RC, Bonnez W, Reichman RC, Garcea RL. Expression of Human Papillomavirus Type 11 L1 Protein in Insect Cells: in Vivo and in Vitro Assembly of Viruslike Particles. Journal of Virology 1993;67 1936-1944.

[27] Zhou J, Stenzel DJ, Sun, XY, Frazer IH. Synthesis and Assembly of Infectious Bovine Papillomavirus Particles in Vitro. Journal of General Virology 1993;74 763-768.

[28] Hagensee ME, Olson NH, Baker TS, Galloway DA. Three-dimensional Structure of Vaccinia Virus-produced Human Papillomavirus Type 1 Capsids. Journal of Virology 1994;68 4503-4505.

[29] Roden RB, Weissinger EM, Henderson DW, Booy F, Kirnbauer R, Mushinski JF, Lowy DR, Schiller Jt. Neutralization of Bovine Papillomavirus by Antibodies to L1 and L2 Capsid Proteins. Journal of Virology 1994;68 7570-7574.

[30] Campo MS. Animal Models of Papillomavirus Pathogenesis. Virus Research 2002;89 249-261.

[31] Roperto S, Borzacchiello G, Brun R, Leonardi L, Maiolino P, Martano M, Paciello O, Papparella S, Restucci B, Russo V, Salvatore G, Urraro C, Roperto F. A Review of Bovine Urothelial Tumors and Tumor-Like Lesions of the Urinary Bladder. Journal of Comparative Pathology 2010;142 95-108.

[32] Pamukcu AM, Price JM, Bryan GT. Naturally Occurring and Bracken Fern Induced Bovine Urinary Bladder Tumors. Veterinary Pathology 1976;13 110-122.

[33] Campo MS, O'neil BW, Barron RJ, Jarrett WF. Experimental Reproduction of the Papilloma-carcinoma Complex of the Alimentary Canal in Cattle. Carcinogenesis 1994;15 1597-1601.

[34] Campo MS. Bovine Papillomavirus and Cancer. Veterinary Journal 1997;154 175-188.

[35] Borzacchiello G, Ambrosio V, Roperto S, Poggiali F, Tsirimonakis E, Venuti A, et al. Bovine Papillomavirus Type 4 in Oesophageal Papillomas of Cattle from the South of Italy. Journal of Comparative Pathology 2003;128 203-206.

[36] Roperto S, Russo V, Borzacchiello G, Sandulli S, De Martino L, Roperto F. Infezione Batteriche Della Vescica in Bovini Affetti da Tumori Uroteliale. Proceedings of the Annual Meeting of Italian Society of Veterinary Sciences 2006;60 99-100.

[37] Pfister H, Linz U, Gissmann L, Huchthausen B, Hoffman D, Zur Hausen H. Partial Characterization of a New Type of Bovine Papillomavirus. Virology 1979;96 1-8.

[38] Campo MS, Moar MH, Jarrett WFH, Laird HM. A New Papillomavirus Associated with Alimentary Cancer in Cattle. Nature 1980;286 180-182.

[39] Campo MS, Moar MH, Laird HM, Jarrett WFH. Molecular Heterogeneity and Lesion Site Specificity of Cutaneous Bovine Papillomaviruses. Virology 1981;113 323-335. 
[40] Campo MS, Coggins LW. Molecular Cloning of Bovine Papillomavirus Genomes and Comparison of their Sequence Homologies by Heteroduplex Mapping. Journal of General Virology 1982;63 255-264.

[41] Chen EY, Howley PM, Levinson AD, Seeburg PH. The Primary Structure and Genetic Organization of the Bovine Papillomavirus Type 1 Genome. Nature 1982;299 529-534.

[42] Jarrett WFH, Campo MS, O'neil BW, Laird HM, Coggins LW. A Novel Bovine Papillomavirus (BPV6) Causing True Epithelial Papillomas of the Mammary Gland Skin: a Member of a Proposed New BPV Subgroup. Virology 1984;136 255-264.

[43] Antonsson A, Hansson BG. Healthy Skin of Many Animal Species Harbors Papillomaviruses which are Closely Related to their Human Counterparts. Journal of Virology 2002;76 12537-42.

[44] Ogawa T, Tomita Y, Okada M, Shinozaki K, Kubonoya H, Kaiho I, Shirasawa H. Broad-spectrum Detection of Papillomaviruses in Bovine Teat Papillomas and Healthy Teat Skin. Journal of General Virology 2004;85 2191-2197.

[45] Maeda Y, Shibahara T, Wada Y, Kadota K, Kanno T, Uchida I, Hatama S. An Outbreak of Teat Papillomatosis in Cattle Caused by Bovine Papilloma Virus (BPV) Type 6 and Unclassified BPVs. Veterinary Microbiology 2007;121 242-248.

[46] Claus MP, Vivian D, Lunardi M, Alfieri AF, Alfieri AA. Phylogenetic Analysis of Bovine Papillomavirus Associated with Skin Warts in Cattle Herds From the State of Paraná. Pesquisa Veterinária Brasileira 2007;27 314-318.

[47] Claus MP, Lunardi M, Alfieri AF, Sartori D, Fungaro MHP, Alfieri AA. Identification of the Recently Described new Type of Bovine Papillomavirus (BPV8) in Brazilian Beef Cattle Herd. Pesquisa Veterinária Brasileira 2009;29 25-28.

[48] Claus MP, Lunardi M, Alfieri AF, Ferracin LM, Fungaro MHP, Alfieri AA. Identification of Unreported Putative new Bovine Papillomavirus Types in Brazilian Cattle Herds. Veterinary Microbiology 2008;132 396-401.

[49] Lunardi M, Claus MP, Alfieri AA, Fungaro MHP, Alfieri AF. Phylogenetic Position of an Uncharacterized Brazilian Strain of Bovine Papillomavirus in the Genus Xipapillomavirus Based on Sequencing of the L1 Open Reading Frame. Genetics and Molecular Biology 2010;33 745-749.

[50] Ogawa T, Tomita Y, Okada M, Shirasawa H. Complete Genome and Phylogenetic Position of Bovine Papillomavirus Type 7. Journal of General Virology 2007;88 1934-1938.

[51] Tomita Y, Literak I, Ogawa T, Jin Z, Shirasawa H. Complete Genomes and Phylogenetic Positions of Bovine Papillomavirus Type 8 and a Variant Type from a European Bison. Virus Genes 2007;35 243-249. 
[52] Hatama S, Nobumoto K, Kanno T. Genomic and Phylogenetic Analysis of Two Novel Bovine Papillomaviruses, BPV9 and BPV10. Journal of General Virology 2008;89 158-163.

[53] Hatama S, Ishihara R, Ueda Y, Kanno T, Uchida I. Detection of a Novel Bovine Papillomavirus type 11 (BPV11) Using Xipapillomavirus Consensus Polymerase Chain Reaction Primers. Archives of Virology 2011;156 1281- 1285.

[54] Zhu W, Dong J, Shimizu E, Hatama S, Kadota K, Goto Y, Haga T. Characterization of Novel Bovine Papillomavirus Type 12 (BPV-12) Causing Epithelial Papilloma. Archives of Virology 2012;157 85-91.

[55] Lunardi M, Alfieri AA, Otonel RAA, de Alcântara BK, Rodrigues WB, de Miranda AB, Alfieri AF. Genetic Characterisation of a Novel Bovine Papillomavirus Member of the Deltapapillomavirus Genus. Veterinary Microbiology 2012, http://dx.doi.org/ 10.1016/j.vetmic.2012.08.030.

[56] Narechania A, Terai M, Chen Z, DeSalle R, Burk RD. Lack of the Canonical pRBbinding Domain in the E7 ORF of Artiodactyl Papillomaviruses is Associated with the Development of Fibropapillomas. The Journal of General Virology 2004;85 1243-1250.

[57] dos Santos RCS, Lindsey CJ, Ferraz OP, Pinto JR, Mirandola RS, Benesi FJ, Birgel EH, Pereira CAB, Beçak W. Bovine Papillomavirus Transmission and Chromosomal Aberrations: an Experimental Model. Journal of General Virology 1998;79 2127-2135.

[58] Wosiacki SR, Barreiros MAB, Alfieri AF, Alfieri AA. Semi-Nested-PCR for Detection and Typing of Bovine Papillomavirus Type 2 in Urinary Bladder and Whole Blood from Cattle with Enzootic Haematuria. Journal of Virological Methods 2005;126 215-219.

[59] Wosiacki SR, Claus MP, Alfieri AF, Alfieri AA. Bovine Papillomavirus Type 2 Detection in the Urinary Bladder of Cattle with Chronic Enzootic Haematuria. Memórias do Instituto Oswaldo Cruz 2006;101 635-638.

[60] de Carvalho C, de Freitas AC, Brunner O, Góes LGB, Cavalcante AY, Beçak W, dos Santos RCS. Bovine Papillomavirus Type 2 in Reproductive Tract and Gametes of Slaughtered Bovine Females. Brazilian Journal of Microbiology 2003;34 82-84.

[61] de Freitas AC, de Carvalho C, Brunner O, Birgel-Junior EH, Dellalibera AMMP, Benesi FJ, Gregory L, Beçak W, dos Santos RCS. Viral DNA Sequences in Peripheral Blood and Vertical Transmission of the Virus: a Discussion About BPV1. Brazilian Journal of Microbiology 2003;34 76-78.

[62] Yaguiu A, de Carvalho C, de Freitas AC, Góes LGB, Dagli MLZ, Jr Birgel EH, Beçak W, dos Santos, RCS. PapillomatosIs in Cattle: in Situ Detection of Bovine Papillomavirus DNA Sequences in Reproductive Tissues. Brazilian Journal of Morphological Sciences 2006;23 525-529. 
[63] Yaguiu A, Dagli ML, Birgel EH, Jr., Alves Reis BC, Ferraz OP, Pituco EM, et al. Simultaneous Presence of Bovine Papillomavirus and Bovine Leukemia Virus in Different Bovine Tissues: in Situ Hybridization and Cytogenetic Analysis. Genetics and Molecular Research 2008;7 487-97.

[64] Lindsey CL, Almeida ME, Vicari CF, Carvalho C, Yaguiu A, Freitas AC, Beçak W, Stocco RC. Bovine Papillomavirus DNA in Milk, Blood, Urine, Semen, and Spermatozoa of Bovine Papillomavirus-infected Animals. Genetics and Molecular Research 2009;8 310-318.

[65] Carvalho CC, Batista MV, Silva MA, Balbino VQ, Freitas AC. Detection of Bovine Papillomavirus Types, Co-Infection and a Putative New BPV11 Subtype in Cattle. Transboundary and Emerging Diseases 2012;59 441-447.

[66] Claus MP, Lunardi M, Alfieri AA, Otonel RAA, Ferracin LM, Pelegrinelli Fungaro $\mathrm{MH}$, Alfieri AF. A Bovine Teat Papilloma Specimen Harboring Deltapapillomavirus (BPV-1) and Xipapillomavirus (BPV-6) Representatives. Brazilian Archives of Biology and Technology 2009;52 87-91.

[67] Claus MP, Lunardi M, Alfieri AA, Otonel RAA, Sartori D, Fungaro MHP, Alfieri AF. Multiple Bovine Papillomavirus Infections Associated with Cutaneous Papillomatosis in Brazilian Cattle Herds. Brazilian Archives of Biology and Technology 2009;52 93-98.

[68] Schmitt M, Fiedler V, Muller M. Prevalence of BPV Genotypes in a German Cowshed Determined by a Novel Multiplex BPV Genotyping Assay. Journal of Virological Methods 2010;170 67-72.

[69] Antonsson A, Forslund O, Ekberg H, Sterner G, Hansson BG. The Ubiquity and Impressive Genomic Diversity of Human Skin Papillomaviruses Suggest a Commensalic Nature of These Viruses. Journal of Virology 2000;74 11636-11641.

[70] Chambers G, Ellsmore VA, O'Brien PM, Reid SWJ, Love S, Campo MS, Nasir L. Association of Bovine Papillomavirus with the Equine Sarcoid. Journal of General Virology 2003;84 1055-1062.

[71] van Dyk E, Bosman AM, van Wilpe E, Williams JH, Bengis RG, van Heerden J, et al. Detection and Characterisation of Papillomavirus in Skin Lesions of Giraffe and Sable Antelope in South Africa. Journal of the South African Veterinary Association 2011;82 80-85.

[72] Pangty K, Singh S, Goswami R, Saikumar G, Somvanshi R. Detection of BPV-1 and-2 and Quantification of BPV-1 by Real-Time PCR in Cutaneous Warts in Cattle and Buffaloes. Transboundary and Emerging Diseases 2010;57 185-96.

[73] Munday JS, Knight CG. Amplification of Feline Sarcoid-associated Papillomavirus DNA Sequences from Bovine Skin. Veterinary Dermatology 2010;21 341-344. 
[74] Teifke JP, Kidney BA, Lohr CV, Yager JA. Detection of Papillomavirus-DNA in Mesenchymal Tumour Cells and not in the Hyperplastic Epithelium of Feline Sarcoids. Veterinay Dermatology 2003;14 47-56.

[75] da Silva MA, Carvalho CC, Coutinho LC, Reis MC, de Aragão Batista MV, de Castro RS, Dos Anjos FB, de Freitas AC. Co-infection of Bovine Papillomavirus and FelineAssociated Papillomavirus in Bovine Cutaneous Warts. Transboundary and Emerging Diseases. 2012. doi: 10.1111/j.1865-1682.2012.01307.x.

[76] Nicholls PK, Stanley MA. The Immunology of Animal Papillomaviruses. Veterinary Immunology and Immunopathology 2000;73 101-27.

[77] zur Hausen H. Papillomaviruses-to Vaccination and Beyond. Biochemistry-Moscow 2008;73 498-503.

[78] Harper DM, Franco EL, Wheeler C, Ferris DG, Jenkins D, Schuind A, Zahaf T, Innis B, Naud P, De Carvalho NS, Roteli-Martins CM, Teixeira J, Blatter MM, Korn AP, Quint W, Dubin G. Efficacy of a Bivalent L1 Virus-like Particle Vaccine in Prevention of Infection with Human Papillomavirus Types 16 and 18 in Young Women: a Randomised Controlled Trial. Lancet 2004;364 1757-1765.

[79] Villa LL, Costa RLR, Petta CA, Andrade RP, Ault KA, Giuliano AR, Wheeler CM, Koutsky LA, Malm C, Lehtinen M, Skjeldestad FE, Olsson SE, Steinwall M, Brown DR, Kurman RJ, Ronnett BM, Stoler MH, Ferenczy A, Harper DM, Tamms GM, Yu J, Lupinacci L, Railkar R, Taddeo FJ, Jansen KU, Esser MT, Sings HL, Saah AJ, Barr E. Prophylactic Quadrivalent Human Papillomavirus (types 6, 11, 16, and 18) L1 Viruslike Particle Vaccine in Young Women: a Randomised Double-blind Placebo-controlled Multicentre Phase II Efficacy Trial. Lancet Oncology 2005;6 271-278.

[80] Campo MS, Grindlay GJ, Oneil BW, Chandrachud LM, Mcgarvie GM, Jarrett WFH. Prophylactic and Therapeutic Vaccination against a Mucosal Papillomavirus. Journal of General Virology 1993;74 945-953.

[81] Jarrett WFH, Smith KT, Oneil BW, Gaukroger JM, Chandrachud LM, Grindlay GJ, McGarvie GM, Campo MS. Studies on Vaccination against Papillomaviruses - Prophylactic and Therapeutic Vaccination with Recombinant Structural Proteins. Virology 1991;184 33-42.

[82] Pilacinski WP, Glassman DL, Glassman KF, Reed DE, Lum MA, Marshall RF, Muscoplat CC, Faras AJ. Immunization against Bovine Papillomavirus Infection. Ciba Foundation Symposium 1986;120 136-156.

[83] Kirnbauer R, Chandrachud LM, ONeil BW, Wagner ER, Grindlay GJ, Armstrong A, McGarvie GM, Schiller JT, Lowy DR, Campo MS. Virus-like Particles of Bovine Papillomavirus Type 4 in Prophylactic and Therapeutic Immunization. Virology 1996;219 37-44. 
[84] Love AJ, Chapman SN, Matic S, Noris E, Lomonossoff GP, Taliansky M. In Planta Production of a Candidate Vaccine against Bovine Papillomavirus Type 1. Planta. 2012. doi: 10.1007/s00425-012-1692-0.

[85] Borzacchiello G, Roperto F, Nasir L, Campo MS. Human Papillomavirus Research: Do we Still Need Animal Models? International Journal of Cancer 2009;125 739-740.

[86] Campo MS. Vaccination against Papillomavirus in Cattle. Clinics in Dermatology 1997;15 275-283.

[87] Campo MS, Roden RB. Papillomavirus Prophylactic Vaccines: Established Successes, New Approaches. Journal of Virology 2010;84 1214-1220.

[88] Gaukroger JM, Chandrachud LM, O'Neil BW, Grindlay GJ, Knowles G, Campo MS. Vaccination of Cattle with Bovine Papillomavirus Type 4 L2 Elicits the Production of Virus-neutralizing Antibodies. The Journal of General Virology 1996;77 1577-1583.

[89] Embers ME, Budgeon LR, Pickel M, Christensen ND. Protective Immunity to Rabbit Oral and Cutaneous Papillomaviruses by Immunization with Short Peptides of L2, the Minor Capsid Protein. Journal of Virology 2002;76 9798-9805. 